\title{
O gênero Nesticella Lehtinen \& Saaristo (Araneae, Nesticidae) no Brasil
}

\author{
Everton N. L. Rodrigues 1, 2 \& Erica H. Buckup ${ }^{2}$
}

\begin{abstract}
1 Programa de Pós-Graduação em Biologia Animal, Departamento de Zoologia, Instituto de Biociências, Universidade Federal do Rio Grande do Sul. Avenida Bento Gonçalves 9500, Bloco IV, Prédio 43435, 91501-970 Porto Alegre, Rio Grande do Sul, Brasil. Bolsista do CNPq. E-mail: enlrodrigues@yahoo.com.br

${ }^{2}$ Museu de Ciências Naturais, Fundação Zoobotânica do Rio Grande do Sul. Rua Doutor Salvador França 1427, 90690-000 Porto Alegre, Rio Grande do Sul, Brasil. E-mail: erica@fzb.rs.gov.br
\end{abstract}

\begin{abstract}
The genus Nesticella Lehtinen \& Saaristo (Araneae, Nesticidae) in Brazil. The genus Nesticella is recorded for the first time from Brazil. Two new species are described and illustrated: Nesticella murici sp. nov. from Bahia, Alagoas and Sergipe, based on males and female and Nesticella ducke sp. nov. from Amazonas, on a female. KEY WORDS. Neotropical; spiders; taxonomy.
\end{abstract}

RESUMO. O gênero Nesticella é registrado pela primeira vez para o Brasil. Duas espécies novas são descritas e ilustradas: Nesticella murici sp. nov. da Bahia, Alagoas e Sergipe, com base em espécimes de ambos os sexos, e Nesticella ducke sp. nov. do Amazonas, conhecida apenas pela fêmea.

PALAVRAS-CHAVE. Aranhas; Neotropical; taxonomia.

A família Nesticidae Simon, 1894, abrange aranhas caracterizadas pelo clípeo alto, geralmente oito olhos, os médios anteriores menores do que os demais ou reduzidos em número ou perda total nas espécies cavernícolas; pernas sem espinhos, tarsos IV com pente de cerdas indistintamente serrilhadas e presença de cólulo; palpo do macho com paracímbio geralmente muito desenvolvido e palpo da fêmea com unha longa (LeHTineN \& SAARISTO 1980, GerTSCh 1984).

A maioria das espécies habita cavernas, mas também são encontradas na serapilheira de florestas tropicais e subtropicais (Lehtinen \& SaARisto 1980, Gertsch 1984, OtT \& Lise 2002) e no estrato arbóreo-arbustivo no sul do Brasil.

Atualmente a família compreende nove gêneros e 204 espécies. Os gêneros registrados para a Região Neotropical são Nesticus Thorell, 1869, Gaucelmus Keyserling, 1884 e Eidmannella Roewer, 1935 (Platnick 2007). Somente seis espécies desta família estão registradas para o Brasil, cinco pertencentes ao gênero Nesticus segundo Oтт \& Lise (2002) е Eidmannella pallida (Emerton, 1875) por GERTSCH (1984).

O gênero Nesticella foi proposto por Lehtinen \& SAARISTO (1980) com a designação da espécie-tipo N. nepalensis (Hubert, 1973) descrita para o Nepal. O gênero abriga 27 espécies (Platnick 2007), a maioria das regiões tropicais do velho mundo e países asiáticos (Lehtinen \& SAARISTO 1980) e, até o momento, não há registro para as regiões Neotropical e Neártica. Os machos têm paracímbio relativamente menor do que em Nesticus, com o processo dorsal geralmente mais desenvolvido e ramificado do que o ventral, este geralmente com o ápice voltado para a porção interna do paracímbio, podendo ser ramificado ou não, êmbolo afilado e semicircular, apófise tegular presente ou ausente, apófise média presente e condutor apical, desenvolvido; as fêmeas apresentam epígino com larga placa ventral subtriangular, que se estreita gradativamente para trás com ou sem a presença de um pequeno lóbulo ou escapo mediano posterior.

Neste trabalho, o gênero Nesticella é registrado pela primeira vez para a Região Neotropical e são descritas duas espécies novas, procedentes das regiões norte e nordeste do Brasil. Os espécimes estão depositados nas coleções de aranhas do Instituto Butantan, São Paulo, Brasil (IBSP, A.D. Brescovit) e Museu de Ciências Naturais, Fundação Zoobotânica do Rio Grande do Sul, Porto Alegre, Brasil (MCN, E.H. Buckup). A terminologia usada nas descrições segue GerTsch (1984). Para o estudo das estruturas internas da genitália da fêmea, o epígino foi submerso em óleo de cravo por aproximadamente 30 minutos. Medidas são apresentadas em milímetros ( $\mathrm{mm})$.

\section{Nesticella murici sp. nov. Figs $1-8$}

Tipos. Holótipo macho, Estação Ecológica de Murici, Murici $\left(09^{\circ} 15^{\prime} \mathrm{S}-35^{\circ} 51^{\prime} \mathrm{W}\right)$, Alagoas, Brasil, 13-22.IX.2003, Equipe Biota leg. (IBSP 73442). Parátipos: fêmea, com os mesmos dados do holótipo (IBSP 73443); macho, Estação Ecológica da Serra de Itabaiana, Itabaiana $\left(10^{\circ} 40^{\prime} \mathrm{S}-37^{\circ} 25^{\prime} \mathrm{W}\right)$, Sergipe, Brasil, 14-20.IX.1999, A.D. Brescovit leg. (MCN 43324, ex-IBSP).

Etimologia. O substantivo específico em aposição referese à localidade-tipo. 

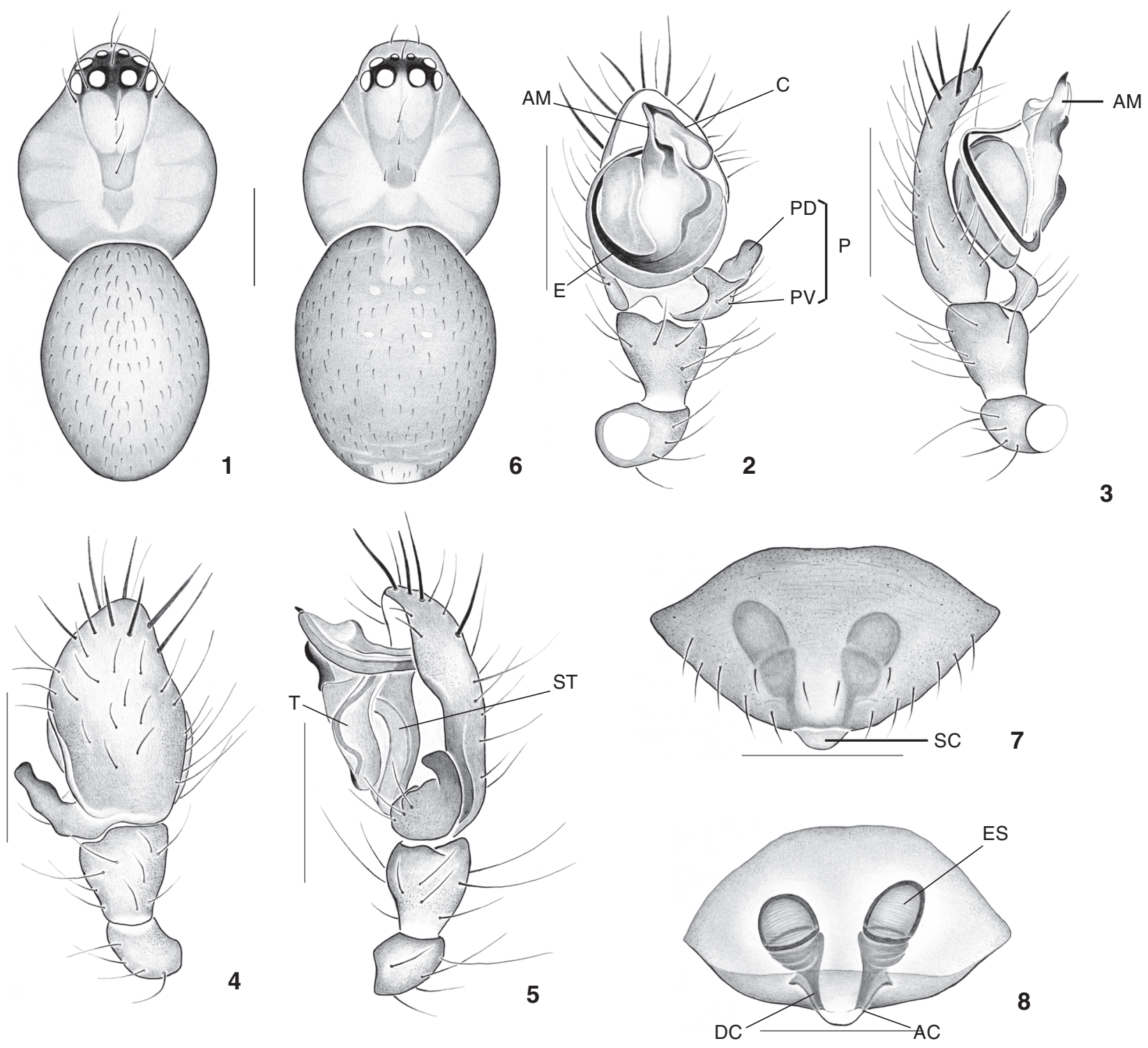

Figuras 1-8. Nesticella murici sp. nov.: (1) macho, corpo, vista dorsal; (2-5) palpo do macho: (2) vista ventral; (3) vista prolateral; (4) vista dorsal; (5) vista retrolateral; (6) fêmea, corpo, vista dorsal; (7 e 8) epígino: (7) vista ventral; (8) vista dorsal, clarificado. (AC) Abertura de copulação, (AM) apófise média, (C) condutor, (DC) ducto de copulação, (E) êmbolo, (ES) espermateca, (P) paracímbio, (PD) processo dorsal, (PV) processo ventral, (SC) escapo, (ST) subtégulo, (T) tégulo. Barras: figuras 1 e $6=0,5 \mathrm{~mm} ; 2-5=0,3 \mathrm{~mm} ; 7$ e $8=0,25 \mathrm{~mm}$.

Diagnose. O palpo do macho de Nesticella murici sp. nov. assemelha-se ao de N. mogera (Yaginuma, 1972) (sensu Lehtinen \& SAARISTO 1980, fig. 7; GerTsCh 1984, figs 196 e 197) e N. marapu Benjamin, 2004 (Benjamin 2004, figs 1 e 2) por apresentar o condutor e apófise média direcionados para o ápice do címbio; separa-se de $N$. mogera pelo paracímbio com processo ventral, distalmente obtuso e pelas margens laterais sinuosas do processo dorsal; condutor longo, quase atingindo o vértice do címbio (Fig. 4); distingue-se de N. marapu pelos ápices dos processos dorsal e ventral do paracímbio não-bifurcados (Figs 2, 4 e 5); o epígino da fêmea assemelha-se ao de $N$. mogera (vide LeHtinen \& SAARISTO 1980, fig. 7) por apresentar escapo, mas difere desta pelos ductos perfazendo três voltas ao redor das espermatecas, estas alongadas (Figs 7 e 8).

Descrição. Holótipo macho. Comprimento total 1,87. Carapaça, comprimento 0,95, largura 0,80, altura 0,37. Clípeo, altura 0,30. Esterno, comprimento 0,60, largura 0,57. Quelícera, comprimento 0,35, largura 0,15. Abdômen, comprimento 0,97, 
largura 0,72 , altura 0,72 . Fórmula das pernas $1 / 4 / 2 / 3$. Comprimento $1 / 2 / 3 / 4$ : fêmures $1,50 / 1,20 / 0,97 / 1,47$; patelas $0,35 / 0,30 /$ 0,27/0,30; tíbias 1,37/1,07/0,77/1,22; metatarsos 1,40/1,02/0,77/ 1,10; tarsos 0,72/0,57/0,50/0,60. Total 5,34/4,16/3,28/4,69. Carapaça (Fig. 1) amarelo-escura com pigmentação cinza nas bordas e na porção mediana; área ocular enegrecida; quadrângulo ocular mais largo $(0,22)$ do que longo $(0,18)$. Fila ocular posterior $(0,37)$ mais larga que a anterior $(0,32)$. OLA e OLP maiores que os demais e OMA os menores. Clípeo alto e projetado. Esterno e enditos amarelo-escuros com pigmentação cinza-escura. Quelíceras amarelo-acinzentadas, promargem com três dentes. Lábio mais largo do que longo, fusionado ao esterno, com rebordo anterior amarelo. Enditos subparalelos. Pernas amareloclaras, com pigmento cinza distalmente, com muitas cerdas. Abdômen suboval (Fig. 1), cinza-escuro, bastante piloso, despigmentado posteriormente. Fiandeiras amarelo-claras, acinzentadas. Cólulo longo com várias cerdas. Palpo do macho (Figs 2-5): címbio com macrocerdas apicais; ápice do processo ventral do paracímbio curvado para dentro, apófise média longa, orientada apicalmente com o ápice ultrapassando o condutor; ducto com apenas uma alça no tégulo; sem apófise tegular.

Parátipo fêmea (Murici, IBSP 73443). Comprimento total 1,97. Carapaça, comprimento 1,07 , largura 0,89 , altura 0,47 . Clípeo, altura 0,15. Esterno, comprimento 0,65, largura 0,60. Quelícera, comprimento 0,35, largura 0,22. Abdômen, comprimento 1,25 , largura 0,92 , altura 0,95 . Perna I esquerda perdida e direita somente com fêmur e patela. Comprimento $1 / 2 / 3 / 4$ : fêmures $1,40 / 1,22 / 0,92 / 1,45$; patelas $0,40 / 0,32 / 0,32 / 0,37$; tíbias - /1,02/0,65/1,00; metatarsos - /0,95/0,70/0,95; tarsos - /0,55/ $0,50 / 0,52$. Total - /4,06/3,09/4,29. Tarso do pedipalpo com unha longa. Carapaça (Fig. 6), coloração semelhante a do macho, área ocular preta, exceto entre os OMP; quadrângulo ocular mais largo $(0,21)$ do que longo $(0,16)$. Fila ocular posterior $(0,37)$ mais larga que a anterior $(0,32)$. OLP maiores que os demais e OMA, os menores. Clípeo projetado. Quelíceras amarelo-acinzentadas, com três dentes na promargem e vários dentículos na retromargem. Enditos, lábio, esterno e pernas como no macho. Abdômen (Fig. 6) cinza-escuro, piloso, despigmentado na região mediana anterior e em uma pequena área posterior. Cólulo longo com várias cerdas. Epígino elevado em relação ao escapo, este situado em um plano inferior ao da placa epiginal (Figs 7 e 8).

Material examinado. Brasil, Bahia: Una (Reserva Biológica do Una, $\left.15^{\circ} 10^{\prime} \mathrm{S}-39^{\circ} 03^{\prime} \mathrm{W}\right)$, macho, 13.IV.1998, A. D. Brescovit et al. leg. (IBSP 18361); macho, Itamarajú (Fazenda Nossa Senhora das Neves), 07.VIII.1978, J.S. Santos leg. em lavoura cacaueira (MCN 10687).

Distribuição. Nordeste do Brasil (Bahia, Alagoas e Sergipe).

\section{Nesticella ducke sp. nov. Figs 9-11}

Tipo. Holótipo fêmea, Reserva Florestal Adolpho Ducke, Manaus, Amazonas, Brasil, 18-25.II.1992, A.D. Brescovit leg. (MCN 22024).
Etimologia. O substantivo específico em aposição referese à localidade-tipo.

Diagnose. O epígino da fêmea de Nesticella ducke sp. nov. distingue-se de $N$. murici, pelos ductos longos, cerca de duas vezes o comprimento dos de $N$. murici, a partir da margem posterior do epígino até a base das espermatecas e pelo maior número de voltas realizadas sobre as mesmas, estas mais afastadas entre si do que as de N. murici (Figs 10 e 11).

Descrição. Holótipo macho. Comprimento total 1,90. Carapaça, comprimento 0,95, largura 0,82, altura 0,37. Clípeo, altura 0,17. Esterno, comprimento 0,55, largura 0,53. Quelícera, comprimento 0,35, largura 0,17. Abdômen, comprimento 1,00, largura 0,97, altura 0,89. Fórmula das pernas $1 / 4 / 2 / 3$. Comprimento $1 / 2 / 3 / 4$ : fêmures $1,25 / 1,05 / 0,82 / 1,22$; patelas $0,37 / 0,35 /$ 0,25/0,27; tíbias 1,20/0,89/0,50/0,97; metatarsos 1,17/0,57/0,55/ 0,82; tarsos 0,60/0,40/0,42/0,52. Total 4,59/3,26/2,54/3,80. Carapaça (Fig. 9) amarela com as bordas e região mediana pigmentadas de cinza; área ocular preta. Quadrângulo ocular mais largo $(0,21)$ do que longo $(0,16)$. Fila ocular posterior $(0,38)$ mais larga que a anterior $(0,35)$. OL e OMP bem maiores do que os OMA. Clípeo projetado. Esterno, amarelo, pigmentado de cinza, fusionado ao lábio e truncado entre as coxas IV; lábio mais largo do que longo com borda anterior amarelo-clara; enditos amarelo-claros e subparalelos. Quelíceras amarelas ligeiramente pigmentadas de cinza na metade basal, promargem com três dentes, retromargem com vários dentículos. Pernas amarelo-claras com os segmentos escurecidos distalmente. Abdômen suboval (Fig. 9) dorsalmente com três indistintas faixas transversais despigmentadas, a primeira na região mediana com prolongamento longitudinal até a margem anterior. Ventre amarelo, manchado de cinza. Fiandeiras amarelo-claras e cólulo pequeno. Epígino estreitando-se gradativamente para a região mediana posterior; aberturas de copulação junto à margem posterior; sem escapo (Figs 10 e 11).

Macho. Desconhecido.

Material examinado. Somente o tipo.

Distribuição. Norte do Brasil (Amazonas).

\section{AGRADECIMENTOS}

Ao curador da coleção do Instituto Butantan Antonio D. Brescovit pelo empréstimo de exemplares e doação de espécime. A Maria Aparecida de Leão Marques (MCN/FZBRS) pela leitura crítica do manuscrito. Aos revisores anônimos pelas sugestões apresentadas. Este trabalho é parte do programa BIOTA/FAPESP - Programa Virtual de Biodiversidade (www.biotasp.org.br).

\section{REFERÊNCIAS BIBLIOGRÁFICAS}

Benjamin, S.P. 2004. Nesticella marapu sp. n., a blind nesticid (Araneae: Nesticidae) from Sumba, Indonesia. Revue Suisse de Zoologie 111 (2): 303-307.

GerTsCH, W.J. 1984. The spider family Nesticidae (Araneae) in North America, Central America, and the West Indies. Bulletin Texas Memorial Museum 31: 1-91.

Revista Brasileira de Zoologia 24 (3): 673-676, setembro 2007 

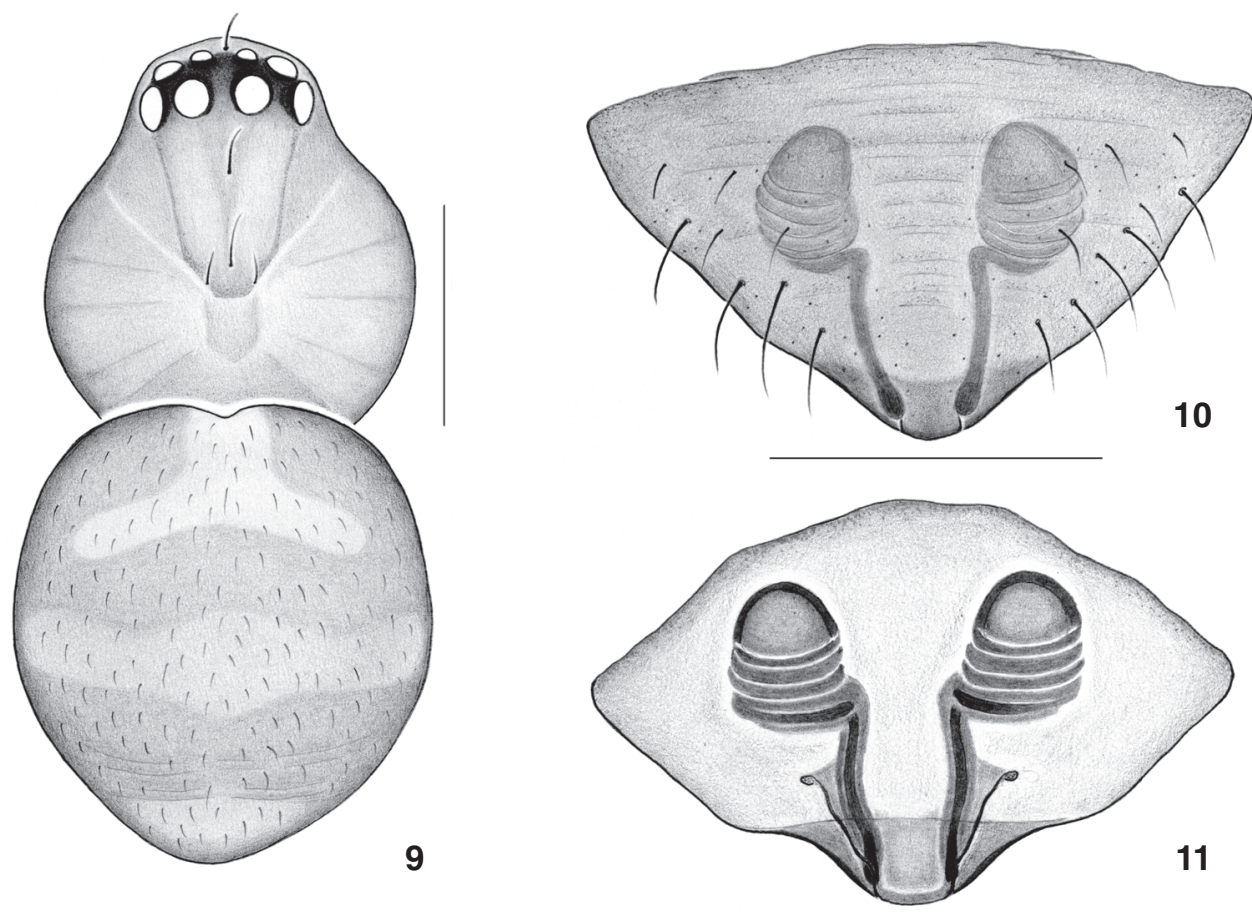

Figuras 9-11. Nesticella ducke sp. nov.: (9) fêmea, corpo, vista dorsal; (10 e 11) epígino: (10) vista ventral; (11) vista dorsal, clarificado. Barras, figura 9: 0,5 mm; 10 e 11: 0,25 mm.

Lehtinen, P.T. \& M.I. SAaristo. 1980. Spiders of the OrientalAustralian region. II. Nesticidae. Annales Zoologigi Fennici 17: 47-66.

Отт, R. \& A.A. Lise. 2002. On Nesticus from meridional South America (Araneae, Nesticidae). Iheringia, Série Zoologia,
92 (4): 59-71.

Platnick, N.I. 2007. The world spider catalog, version 8.0. American Museum of Natural History. Disponível na World Wide Web em: http://research.amnh.org/entomology/ spiders/catalog/index.html [Acessado em 06/VIII/2007].

Recebido em 29.V.2007; aceito em 10.VIII.2007. 